\title{
Letter to the Editor concerning "Risk of revision surgery for adult idiopathic scoliosis: a survival analysis of 517 cases over 25 years" by G. Riouallon et al. (Eur Spine J; 2016;25(8):2527-2534)
}

\author{
Felisa Sánchez-Mariscal ${ }^{1}$ - Alejandro Gomez-Rice ${ }^{1} \cdot$ Enrique Izquierdo $^{1}$ • \\ Javier Pizones $^{1} \cdot$ Lorenzo Zúñiga $^{1} \cdot$ Patricia Álvarez-Gonzalez ${ }^{1}$
}

Received: 3 September 2016/Accepted: 4 October 2016/Published online: 12 October 2016

(C) Springer-Verlag Berlin Heidelberg 2016

\section{Dear Editor,}

We read with great interest the article by Riouallon et al. [1]. We congratulate the authors for the long-term (25 years) idiopathic scoliosis survival study.

However, we would like to address some points that merit more attention.

While in their introduction the authors seem to imply that there are no previous adult deformity survival studies, another previous adult scoliosis survival study is cited in their references [2]. Moreover, we believe relevant published work providing adult scoliosis surgery survival has not been cited by the authors [3].

Although the authors conclude that "the risk of revision surgery is high following surgery for adult scoliosis, and is $18 \%$ after 10 years", this study includes a number of patients who underwent index surgery for adolescent idiopathic scoliosis (range of age 15.2-83.5). Hence, conclusions should be reached regarding idiopathic scoliosis surgery survival instead of adult idiopathic scoliosis survival. Bearing in mind this wide range of age, we cannot help but find the title of the article "Risk of revision surgery for adult idiopathic scoliosis" misleading. We think that to avoid confusion, or misinterpretation, the inclusion of patients operated on idiopathic adolescent scoliosis should have been specified in the title and text; otherwise, many readers may have assumed that only patients whose index surgery was performed in adult age were included for this study.

\section{Compliance with ethical standards}

Funding No funding or grants were received for this publication.

Conflict of interest There is no actual or potential conflict of interest in relation to this publication.

\section{References}

1. Riouallon G, Bouyer B, Wolff S (2016) Risk of revision surgery for adult idiopathic scoliosis: a survival analysis of 517 cases over 25 years. Eur Spine J 25(8):2527-2534. doi:10.1007/s00586-0164505-5

2. Charosky S, Guigui P, Blamoutier A, Roussouly P, Chopin DM, Study Group on Scoliosis (2012) Complications and risk factors of primary adult scoliosis surgery: a multicenter study of 306 patients. Spine 37(8):693-700

3. Sánchez-Mariscal F, Gomez-Rice A, Izquierdo E, Pizones J, Zúñiga L, Álvarez-González P (2014) Survivorship analysis after primary fusion for adult scoliosis. Prognostic factors for reoperation. Spine J 14(8):1629-1634
Felisa Sánchez-Mariscal

f3130@hotmail.com

1 Spinal Unit, Hospital Universitario de Getafe, Carretera de Toledo km 12.5, 28905 Getafe, Madrid, Spain 